\title{
COVID-19: hypofractionation in the Radiation Oncology Department during the 'state of alarm': first 100 patients in a private hospital in Spain
}

\author{
Luis Larrea ${ }^{1}$, Enrique López ${ }^{1}$, Paola Antonini ${ }^{1}$, Verónica González ${ }^{1}$, Miguel Ángel Berenguer ${ }^{1}$, Maria Carmen Baños², Jose Bea² and \\ Jose Domingo ${ }^{2}$
}

${ }^{1}$ Radiation Oncology Department, Hospital Vithas Valencia Consuelo, 46007, Spain

${ }^{2}$ Radiophysics Department, Hospital Vithas Valencia Consuelo, 46007, Spain

\section{Abstract}

During the COVID-19 pandemic, Spain declared a 'state of alarm' on 14 March 2020. In our Radiation Oncology Department, experienced in administering hypofractionated treatments (partial irradiation in breast cancer, moderate hypofractionation in localized prostate cancer, etc), we have increased the hypofractionated treatment indications. We are only deferring the start of non-urgent treatments such as prostate tumours under androgen deprivation or benign brain tumours which are candidates for radiosurgery such as meningiomas or acoustic neuroma.

In this hypofractionation era we find that we have decreased the number of sessions per patient and that we can evaluate the last years with the fractionation index (FI) (calculated by dividing the total number of fractions administered in the department by the total number of patients treated). We have gone from 14.4 in 2018 to 13.78 in 2019 , excluding brachytherapy.

We report the results of the first 100 patients who have experienced radiotherapy treatment since the state of alarm ( 66 women and 34 men). In these patients, the $\mathrm{Fl}$ is $12.12-$ lower than previous years.

Keywords: COVID-19, hypofractionation, Fractionation Index (FI)

\section{Introduction}

In Spain, on 14 March 2020, a 'state of alarm' was declared due to the COVID-19 pandemic, forcing citizens to be confined at home with movement restrictions. Previously, at the Radiation Oncology Department, we established major indication of hypofractionated treatments in the majority of new patients attended, according to the recommendations of national and international societies.

On the other hand, in those patients where it was possible, we delayed some treatments until the end of the maximum contagion period, for example, prostate cancer under androgen deprivation (AD) therapy or with low-grade staging, as well as radiosurgery for benign brain tumours, such as meningioma or acoustic neuroma.

Correspondence to: Verónica González Vidal Email: gonzalezvidalveronica@gmail.com

ecancer 2020, 14:1052

https://doi.org/10.3332/ecancer.2020.1052

Published: $28 / 05 / 2020$

Received: 23/04/2020

Publication costs for this article were supported by ecancer (UK Charity number 1176307).

Copyright: $($ ) the authors; licensee ecancermedicalscience. This is an Open Access article distributed under the terms of the Creative Commons Attribution License (http:// creativecommons.org/licenses/by/3.0), which permits unrestricted use, distribution, and reproduction in any medium, provided the original work is properly cited. 
Our department has two linear accelerators equipped with Image-Guided-Radiation-Therapy (ConeBeamCT) and the ability to perform Intensity-Modulated-Radiation-Therapy (IMRT) and Volumetric-Arc-Therapy (VMAT). We also have brachytherapy equipment for high dose rate and low dose rate. Our experience is to treat an average of 800-1200 patients per year.

\section{Materials and methods}

Between 16 March and 16 April 2020, we analysed the first 100 consecutive patients who began treatment in our department after the declaration of the 'State of Alarm'. We analysed the number of fractions or sessions per patient and treatment during this period. This was defined as 'Fractionation Index' (FI). It is calculated by dividing the total number of sessions by the total number of patients registered in our management information system (Mosaiq ${ }^{\circledR}$-Elekta $\AA$ ). We included all patients treated with external beam radiation therapy, excluding brachytherapy procedures.

Previously, as we were indicating more hypofractionated treatments in this Radiation Oncology Department, we calculate the FI for 2018 and 2019. We reported in 2018, with 1,011 patients a fractionation index of 14.48 sessions per patient, number that decreased in 2019 to 13.78 sessions with 854 treated patients.

The main reason for indicating hypofractionated treatments during the COVID-19 pandemic is to minimise exposure and risk of contagion of patients without reducing the effectiveness of the treatments. Our attitude was to establish a better way to treat all patients who can benefit from radiotherapy; not to delay the onset of any patient whose deferral may worsen the prognosis of their disease; try to help the patient attend treatment as few times as possible and not increasing toxicity and maintaining the possibility of the best result. The hypofractionated treatments we indicated during the time of COVID-19 are supported mainly by international guidelines and phase III clinical trials [1-19].

To preserve the quality criteria of treatments, the tolerance limits protocols, quantitative analyses of normal tissue effects in the clinic and Radiation Therapy Oncology Group were adapted to the new hypofractioned schemes, estimating the biological equivalent dose (BED).

\section{Results}

We report the first 100 patients ( 66 women and 34 men). The mean age in women was 58-year old and it was 66-year old in men.

The number of patients included in each subgroup, treatment intention and tumours location are detailed in Table 1.

Table 1. Treatments performed by intention, techniques and number of sessions.

\begin{tabular}{|c|c|c|c|c|c|}
\hline Tumour location & Treatment intention $(N)$ & Type of treatment $(N)$ & Fractions per Treatment & Total number of fractions & Number of patients \\
\hline Breast & Adjuvant & $\begin{array}{l}\text { APBI (12) } \\
\text { RTC-3D-IMRT (40) }\end{array}$ & $\begin{array}{c}5 \\
15\end{array}$ & 660 & 52 \\
\hline Prostate & $\begin{array}{l}\text { Radical (7) } \\
\text { Biochemical relapse (2) }\end{array}$ & VMAT & $\begin{array}{l}20 \\
25\end{array}$ & $\begin{array}{c}140 \\
50\end{array}$ & 9 \\
\hline $\begin{array}{l}\text { Brain metastases } \\
\text { (oligometastases) }\end{array}$ & Radical & SRS & 1 & 8 & 8 \\
\hline Lung primary & $\begin{array}{l}\text { Palliative (3) } \\
\text { Radical (6) } \\
\text { Adjuvant (1) }\end{array}$ & $\begin{array}{l}\text { RTC-3D (3) } \\
\text { IMRT (6) } \\
\text { IMRT (1) }\end{array}$ & $\begin{array}{c}15-20 \\
20 \\
20 \\
\end{array}$ & $\begin{array}{c}51 \\
120 \\
20 \\
\end{array}$ & 10 \\
\hline Lung metastases & Radical (3) & SBRT & $1-3$ & 7 & 3 \\
\hline Glioblastoma & Relapse (2) & $\begin{array}{l}\text { SRS } \\
\text { FSRS }\end{array}$ & $\begin{array}{l}1 \\
4\end{array}$ & 5 & 2 \\
\hline Larynx & Radical (2) & IMRT & 16 & 32 & 2 \\
\hline $\begin{array}{l}\text { Adrenal metastases } \\
\text { (oligometastases) }\end{array}$ & Radical (2) & SBRT & 3 & 6 & 2 \\
\hline
\end{tabular}


Table 1. Treatments performed by intention, techniques and number of sessions. (Continued)

\begin{tabular}{|l|l|l|c|c|c|}
\hline Skin & Adjuvant & RTC-3D & 23 & 23 \\
\hline Pancreas & Neoadjuvant & IMRT & 15 & 15 \\
\hline Brain hemangiopericytoma & Radical & FSRS & 5 & 5 \\
\hline Parotid gland & Adjuvant & IMRT & 25 & 25 \\
\hline Anal canal & Radical & IMRT & 5 & 1 \\
\hline Supraclavicular tumour & $\begin{array}{l}\text { Radical } \\
\text { (oligometastases) }\end{array}$ & SBRT & 12 & 5 \\
\hline Vaginal recurrence & $\begin{array}{l}\text { Radical } \\
\text { (oligometastases) }\end{array}$ & IMRT & 12 & 1 \\
\hline Total & & & & 12 \\
\hline
\end{tabular}

RTC-3D, Tridimensional Conformal Radiotherapy; APBI, Accelerated Partial Breast Irradiation; IMRT, Intensity-Modulated-Radiation-Therapy; VMAT, Volumetric-Arc-Therapy; SRS, Stereotactic radiosurgery; SBRT, Stereotactic Body Radiation Therapy.

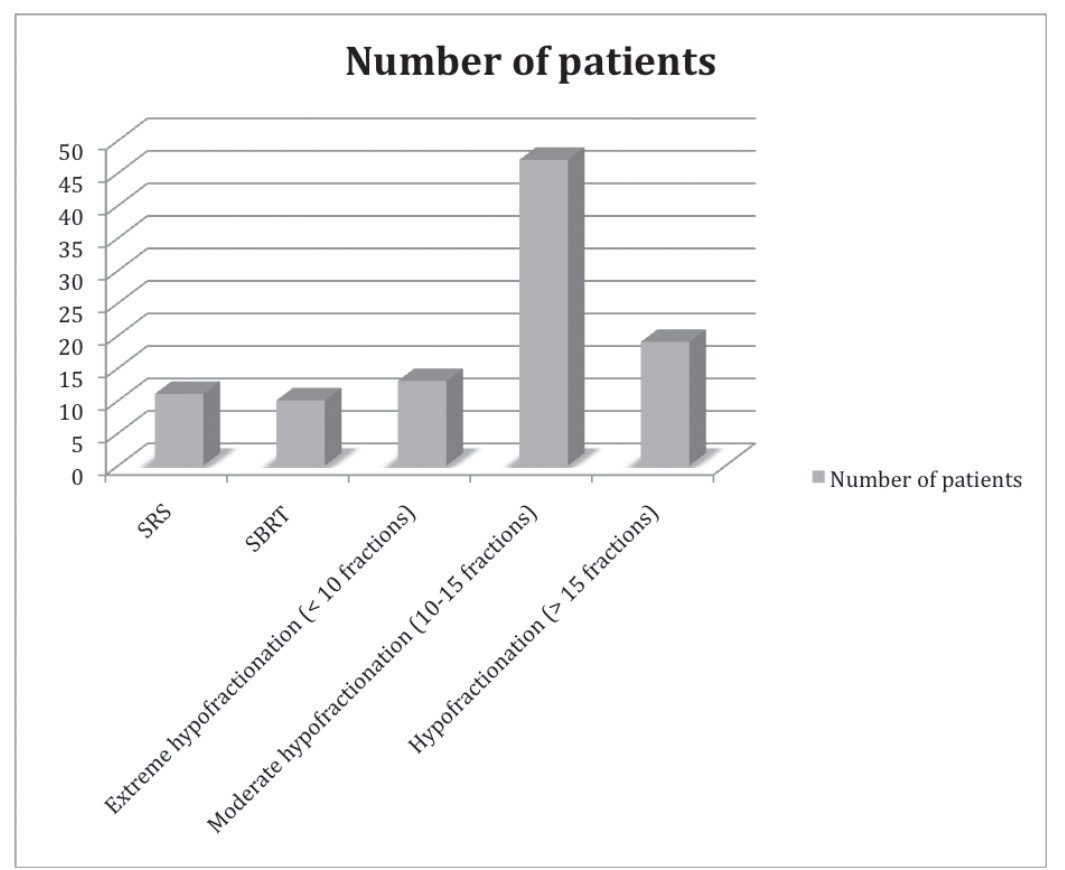

Figure 1. Number of patientes represented according number of sessions and technique.

In summary, treatment indication has been: 55 adjuvant treatments, 18 radicals, 19 oligometastatic, 4 recurrences, 3 palliative and 1 neoadjuvant.

Treatment by techniques: 69 patients had 3D-IMRT, 11 radiosurgery, 10 VMAT, 10 SBRT (Figure 1).

The first 100 patients treated that we evaluated shows that the $\mathrm{Fl}$ is 12.12 sessions per patient, this is a very low average compared to standard fractionation. We consider that these are safe and recognised treatments, recommended in oncology guidelines.

During this time we delayed nine patients, seven patients with prostate cancer in whom indicated external beam radiotherapy has been deferred and two patients with acoustic neuroma. Of these 7 prostate cancer patients, 5 of them we will indicate 20 sessions $(2$ of them are under $\mathrm{AD}$ and 3 low grade) and the other 2 patients will be treated with combined modality (12 sessions and high-dose-rate brachytherapy boost, both are under AD). 
If we include these 7 prostate cancer patients, the FI would be 12.48 fractions per patient, but maybe we will treat some of them with SBRT technique with 5-8 fractions. Adding also 2 SRS, this FI will be lower.

\section{Conclusion}

The current average $\mathrm{Fl}$ is much lower than the average standard treatments.

This change in our prescription using hypofractionated schemes allowed us to treat patients in a more isolated way so they have fewer contacts in the waiting room. Furthermore, it allows us to disinfect the equipment between patients. We had not report COVID-19 among our staff or patients.

In the near future, we also will receive patients who are now suffering delays in diagnosis and surgery, then we will gradually adapt the treatments for them.

Due to the low FI, hypofractionated radiotherapy treatments can be more cost-effective during the COVID-19 pandemic.

FI can be an easy and effective formula to evaluate a radiation therapy department.

\section{Conflicts of interest statement}

Dr Larrea is a member of the ecancer editorial board.

\section{Funding declaration}

No funding to declare.

\section{References}

1. Whelan T, Julian JA, and Berrang TS, et al (2019) External beam accelerated partial breast irradiation versus whole breast irradiation after greast conserving surgery in women with ductal carcinoma in situ and node-negative breast cancer (RAPID): a randomised controlled trial Lancet 394(10215) 2165-2172. https://doi.org/10.1016/S0140-6736(19)32515-2 PMID: 31813635

2. Agrawal RK, Alhasso A, and Barrett-Lee PJ, et al (2011) First results of the randomised UK FAST Trial of Radiotherapy hypofractionation for treatment of early breast cancer (CRKU/04/015) Radiother Oncol 100(1) 93-100 https://doi.org/10.1016/j.radonc.2011.06.026 PMID: 21752481

3. Lyl L, Meattini I, and Marrazzo L, et al (2015) Accelerated partial beast irradiation using intensity-modulated radiotherapy versus whole breast irradiation: 5-year survival analysis of a phase 3 randomised controlled trial Eur J Cancer 51(4) 451-463 https://doi. org/10.1016/j.ejca.2014.12.013

4. Brunt AM, Wheatley D, and Yarnold J, et al (2016) Acute skin toxicity associated with a 1-week scheduke of ehole breast radiotherapy compared with a standard 3-week régimen delivered in the UK FAST-Forward Trial Radiother Oncol 120(1) 114-118 https://doi. org/10.1016/j.radonc.2016.02.027 PMID: 27046390 PMCID: 4998960

5. Freedman GM, White JR, and Arthur DW, et al (2013) Accelerated fractionation with a concurrent boost for early stage breast cancer Radiother Oncol 106(1) 15-20 https://doi.org/10.1016/j.radonc.2012.12.001 PMID: 23333014

6. Baum M, Baum M, Tobias JS, et al (2008) Targeted intra-operative radiotherapy-TARGIT for early breast cancer Ann N Y Acad Sci 1138 132-135 https://doi.org/10.1196/annals.1414.019 PMID: 18837893 
7. Ansari N, Solomon MJ, and Fisher RJ, et al (2017) Acute adverse events and postoperative complications in a randomized trial of preoperative short-course radiotherapy versus long-course chemoradiotherapy for T3 adenocarcinoma of the rectum: Trans-Tasman Radiation Oncology Group Trial (TROG 01.04) Ann Surg 265(5) 882-888 https://doi.org/10.1097/SLA.0000000000001987

8. Videtic GM, Khan I, and McMenemin R, et al (2014) SOCCAR: A randomised phase II trial comparing sequential versus concurrent chemotherapy and radical hypofractionated radiotherapy in patients with inoperable stage III Non-Small Cell Lung Cancer and good performance status Eur J Cancer 50(17) 2939-2949 https://doi.org/10.1016/j.ejca.2014.07.009

9. Maguire J, Khan I, and McMenemin R, et al (2014) SOCCAR: A randomised phase II trial comparing sequential versus concurrent chemotherapy and radical hypofractionated radiotherapy in patients with inoperable stage III Non-Small Cell Lung Cancer and good performance statatus Eur J Cancer 50(17) 2939-2949 https://doi.org/10.1016/j.ejca.2014.07.009 PMID: 25304298

10. Roa W, Kepka L, and Kumar N, et al (2015) International atomic energy agency randomized phase III study of radiation therapy in elderly and/or frail patients with newly diagnosed glioblastoma multiforme J Clin Oncol 33(35) 4145-4150 https://doi.org/10.1200/ JCO.2015.62.6606 PMID: 26392096

11. Parker CC, James ND, and Brawley CD, et al (2018) Radiotherapy to the primary tumour for newly diagnosed, metastasic prostate cancer (STAMPEDE): a randomised controlled phase 3 trial Lancet 392(10162) 2353-2366 https://doi.org/10.1016/S0140-6736(18)32486-3 PMID: 30355464 PMCID: 6269599

12. Thor M, Deasy JO, Paulus R, et al (2019) Tolerance doses for late adverse events after hypofractionated radiotherapy for prostate cancer on trial NRG Oncology/RTOG 0415 Radiother Oncol 135 19-24 https://doi.org/10.1016/j.radonc.2019.02.014 PMID: 31015166 PMCID: 6582638

13. Mitchell DM, Perry L, and Smith S, et al (2009) Assessing the effect of a contouring protocol on postprostatectomy radiotherapy clinical target volumes and interphysician variation Int J Radiat Oncol Biol Phys 75(4) 990-993 https://doi.org/10.1016/j.ijrobp.2008.12.042 PMID: 19345515

14. Spratt DE, Dai DLY, and Den RB, et al (2018) Performance of a prostate cancer genomic classifier in predicting metastasis in men with prostate-specific antigen persistence postprostatectomy Eur Urol 74(1) 107-114 https://doi.org/10.1016/j.eururo.2017.11.024

15. Huddart R, Hall E, and Lewis R, et al (2020) Patient-reported quality of life outcomes in patients treated for muscle-invasive bladder cancer with radiotherapy \pm chemotherapy in the BC2001 phase III randomised controlled trial Eur Urol https://doi.org/10.1016/j. eururo.2019.11.001

16. Pollicino CA, Turner SL, and Roos DE (2005) Costing the components of pain management: analysis of Trans-Tasman Radiation Oncology Group trial (TROG 96.05): one versus five fractions for neuropathic bone pain Radiother Oncol 76(3) 264-269 https://doi. org/10.1016/j.radonc.2005.07.003 PMID: 16153729

17. Hoskin P, Misra V, and Hopkins K, et al (2017) SCORAD III: Randomized noninferiority phase III trial of single-dose radiotherapy (RT) compared to multifraction RT in patients (pts) with metastatic spinal canal compression (SCC) J Clin Oncol 35 18_suppl https://doi. org/10.1200/JCO.2017.35.15_suppl.LBA10004

18. Porceddu SV, Rosser B, and Burmeister BH, et al (2007) Hypofractionated radiotherapy for the palliation of advanced head and neck cancer in patients unsuitable for curative treatment--"Hypo Trial" Radiother Oncol 85(3) 456-462 https://doi.org/10.1016/j. radonc.2007.10.020 PMID: 18036689

19. Sapienza LG, Ning MS, and Jhingran A, et al (2018) Short-course palliative radiation therapy leads to excellent bleeding control: a single centre retrospective study Clin Transl Radiat Oncol 14 40-46 https://doi.org/10.1016/j.ctro.2018.11.007 PMID: 30555940 PMCID: 6275209 